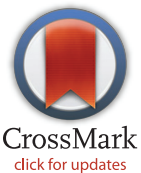

click for updates
RESEARCH ARTICLE

\section{Do Pneumococcal Conjugate Vaccines Represent Good Value for Money in a Lower- Middle Income Country? A Cost-Utility Analysis in the Philippines}

\author{
Manuel Alexander Haasis ${ }^{1}{ }^{*}$, Joyce Anne Ceria ${ }^{1}$, Wantanee Kulpeng ${ }^{2}$, \\ Yot Teerawattananon ${ }^{2}$, Marissa Alejandria ${ }^{3}$
}

1 National Center for Pharmaceutical Access and Management (NCPAM), Department of Health, Manila, Philippines, 2 Health Intervention and Technology Assessment Program (HITAP), Department of Health, Ministry of Public Health, Nonthaburi, Thailand, 3 Institute of Clinical Epidemiology-National Institutes of Health (NIH), University of the Philippines, Manila, Philippines

*amhaasis@gmail.com

\section{Abstract}

Citation: Haasis MA, Ceria JA, Kulpeng W, Teerawattananon Y, Alejandria M (2015) Do Pneumococcal Conjugate Vaccines Represent Good Value for Money in a Lower-Middle Income Country? A Cost-Utility Analysis in the Philippines. PLoS ONE 10(7): e0131156. doi:10.1371/journal.pone. 0131156

Academic Editor: Bernard Beall, Centers for Disease Control \& Prevention, UNITED STATES

Received: February 25, 2015

Accepted: May 29, 2015

Published: July 1, 2015

Copyright: @ 2015 Haasis et al. This is an open access article distributed under the terms of the Creative Commons Attribution License, which permits unrestricted use, distribution, and reproduction in any medium, provided the original author and source are credited.

Data Availability Statement: All relevant data are within the paper and its Supporting Information files.

Funding: This work was supported by the Rockefeller Foundation, the National Institute for Health and Care Excellence (NICE) International, World Health Organization (WHO), Health Intervention and Technology Assessment Program (HITAP), and the Department of Health Philippines. The views expressed in the publication are those of the authors and not necessarily those of the supporting institutions. WHO and Rockefeller Foundation had no role in study design, data

\section{Objectives}

The objective of this study is to assess the value for money of introducing pneumococcal conjugate vaccines as part of the immunization program in a lower-middle income country, the Philippines, which is not eligible for GAVI support and lower vaccine prices. It also includes the newest clinical evidence evaluating the efficacy of PCV10, which is lacking in other previous studies.

\section{Methods}

A cost-utility analysis was conducted. A Markov simulation model was constructed to examine the costs and consequences of PCV10 and PCV13 against the current scenario of no $P C V$ vaccination for a lifetime horizon. A health system perspective was employed to explore different funding schemes, which include universal or partial vaccination coverage subsidized by the government. Results were presented as incremental cost-effectiveness ratios (ICERs) in Philippine peso (Php) per QALY gained (1 USD = 44.20 Php). Probabilistic sensitivity analysis was performed to determine the impact of parameter uncertainty.

\section{Results}

With universal vaccination at a cost per dose of Php 624 for PCV10 and Php 700 for PCV13, both PCVs are cost-effective compared to no vaccination given the ceiling threshold of Php 120,000 per QALY gained, yielding ICERs of Php 68,182 and Php 54,510 for PCV10 and PCV13, respectively. Partial vaccination of $25 \%$ of the birth cohort resulted in significantly higher ICER values (Php 112,640 for PCV10 and Php 84,654 for PCV13) due to loss of herd protection. The budget impact analysis reveals that universal vaccination 
collection and analysis, decision to publish, or preparation of the manuscript.

Competing Interests: The authors have declared that no competing interests exist. would cost Php 3.87 billion to 4.34 billion per annual, or 1.6 to 1.8 times the budget of the current national vaccination program.

\section{Conclusion}

The inclusion of $\mathrm{PCV}$ in the national immunization program is recommended. PCV13 achieved better value for money compared to PCV10. However, the affordability and sustainability of PCV implementation over the long-term should be considered by decision makers.

\section{Introduction}

Streptococcus pneumoniae (S. pneumoniae) can cause invasive pneumococcal diseases including bacterial meningitis, bacteremia and sepsis, as well as non-invasive pneumococcal diseases, such as pneumonia and acute otitis media (AOM). Pneumococcal conjugate vaccines (PCV) have been found safe and effective in preventing $S$. pneumoniae-related diseases in young children [1-3]. In addition to this direct vaccine effect, indirect vaccine effects, in particular herd protection, have also been documented. Clinical studies have shown that vaccinating infants and young children with PCV can reduce transmission of the bacterium and disease to unvaccinated populations $[4,5]$.

As a lower-middle income country, the Philippines is not eligible for GAVI support. Therefore, the Philippines faces substantial financial barriers to PCV implementation. As a result, the Philippine government is currently piloting PCV in only selected regions covering approximately $25 \%-30 \%$ of the total of 2 million eligible infants in the country [6]. In addition, the Philippine government remains undecided between the two vaccines available in the market and opted to pilot both the 10- and 13-valent vaccines in the national vaccination program.

A number of economic evaluations of PCV vaccination have been done worldwide. However, most studies used clinical outcomes derived from clinical studies of PCV7 and extrapolated clinical benefits for PCV10 and PCV13 [7-11]. This is because there was no randomized controlled trial (RCT) that directly assessed the benefit of PCV10 and PCV13. A recently published RCT on PCV10 versus hepatitis control vaccine demonstrates a higher vaccine efficacy against AOM compared to previous RCTs of PCVs (all seven-valent) $[12,13]$. This timely economic evaluation aims to inform immunization implementation strategies regarding the likely impact, value for money and budget implications of PCV vaccination in the Philippines. The study focuses on whether to introduce a universal versus partial PCV vaccination program as well as on informing which vaccine type should represent the best value for money given the new information.

\section{Materials and Methods}

\section{Markov Model}

A Markov model with one-year cycle length adapted from a prior study [14] was used to estimate the lifetime costs and outcomes for PCV10 and PCV13 compared to 'no vaccination', consisting of three major health states: good health, S. pneumoniae infection and death (Fig 1). Whilst the model structure for this study was adapted from Thai setting, this model has been validated in consultation meetings by Philippine experts including infectious disease specialists, epidemiologists, health economists, and policy decision makers.

It was assumed that only one infection per cycle could occur. The analysis adopted a health system perspective, which includes direct costs of PCV related treatments and of the 


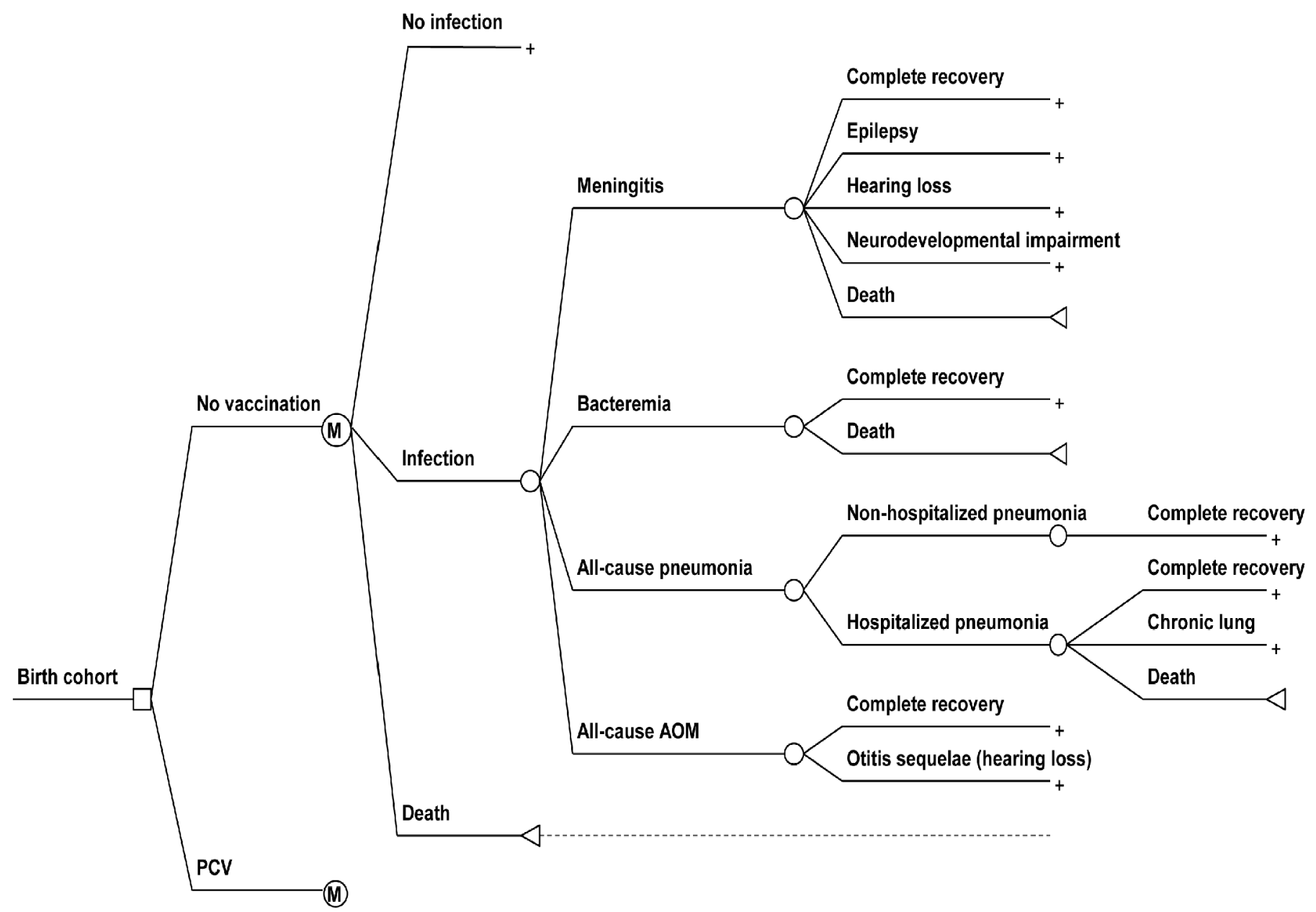

Fig 1. Markov model used for assessing the health and economic impact of pneumococcal conjugate vaccine (PCV) vaccination compared to 'no vaccination'. The structure of the PCV node was omitted in the figure, as it is identical to the 'no vaccination' node.

doi:10.1371/journal.pone.0131156.g001

vaccination program. An annual discount rate of 3.5\% for both costs and outcomes was applied based on recommendations by the Formulary Executive Council (FEC), which is responsible for the development of the Philippine National Formulary. All costs are presented for the year 2013.

\section{Intervention}

The effects of switching from no vaccination to either PCV10 or PCV13 were evaluated, alternatively with and without indirect effects. For this study, a 2-dose primary series at 1.5 and 2.5 months, plus a booster dose at 9 months of age $(2+1)$ was considered. Vaccine coverage rates of $90 \%, 88 \%$ and $86 \%$ for the first, second and booster dose, respectively, were assumed to correspond the achieved 2013 coverage rates for DPT-HepB-Hib vaccination for the first two doses and for measles vaccination administered at the same time as the booster dose [15].

\section{Policy scenarios}

The study employs two potential policy scenarios, which examine the impact of different vaccination coverage rates on health outcomes, cost-effectiveness and government budget. 
Scenario 1 (Universal coverage): 100\% of the country's birth cohort will receive PCV vaccination fully funded by the government (vaccination is free of charge to the vaccinee).

Scenario 2 (Partial coverage, status quo): $25 \%$ of the country's birth cohort will receive PCV vaccination fully funded by the government. The remaining $75 \%$ of the birth cohort will not be vaccinated.

\section{Model input parameters}

Epidemiological parameters. A summary of the epidemiological parameters used in the analysis is provided in Table 1. Philippine-specific data on the incidence of pneumococcal meningitis, bacteremia and sepsis in children $<5$ years were taken from the PneumoNet study [16]. No published data were available on the IPD incidence among Filipinos older than 5 years of age. Therefore, incidences of pneumococcal meningitis and bacteremia/sepsis in the $>5$ age groups were derived based on Thai data [17-19] and were adjusted according to the following formula:

(1) PHL pn. meningitis incidence for age groups $\geq 5$

$$
=\text { Thai pn. meningitis incidence } \times \frac{\text { PHL pn. meningitis incidence }<5}{\text { Thai pn. meningitis incidence }<5}
$$

(2) PHL pn. bacteremia incidence for age groups $\geq 5$

$$
=\text { Thai pn. bacteremia incidence } \times \frac{\text { PHL pn. bacteremia incidence }<5}{\text { Thai pn. bacteremia incidence }<5}
$$

All meningitis and bacteremia/sepsis cases were assumed to have required hospitalization. Due to the lack of local information of sequelae, Thai data were used. Case-fatality ratios (CFR) for meningitis and bacteremia/sepsis were derived from the PneumoNet study [16].

All-cause hospitalized pneumonia incidences were gathered from the PneumoNet study and anonymized insurance claims were obtained from the Philippine Health Insurance Corporation (PhilHealth) [16]. Data on non-hospitalized pneumonia was unavailable; thus, information was obtained through an expert panel of infectious disease specialists who estimated a 60:40 ratio of hospitalized to non-hospitalized pneumonia cases in the Philippines. The probability of dying from hospitalized pneumonia was estimated as $2.15 \%[23,24]$.

All-cause AOM incidence was derived from the 2012 national cross-sectional survey of 2,000 children in community health centers and schools in the Philippines [20]. It was assumed that none of the AOM cases were severe enough to require hospitalization or to cause death. According to global estimates, AOM occurs regularly in younger age groups [26]; thus, incidence of AOM was assumed to be zero for individuals that were 12 years or older.

The distribution of serotypes in invasive disease was taken from a comprehensive laboratory-based surveillance study involving 42 hospitals across the Philippines (Fig 2) [27]. The vaccine-type IPD coverage of PCV7, PCV10, and PCV13 was computed for different age groups (S1 Table).

Direct effects (vaccine efficacy). Due to lacking evidence on vaccine efficacy (VE) for the $3+0$ dosing schedule, efficacy of a 2-dose primary series plus a booster dose $(2+1)$ was used. All efficacy estimates were based on the intention-to-treat (ITT) population.

For PCV13, demonstration of VE is based on non-inferior immunogenicity compared with PCV7 rather than efficacy trials measuring clinical endpoints [28, 29]. However, evidence supporting the effectiveness of PCV13 for covered serotypes has been documented in various 


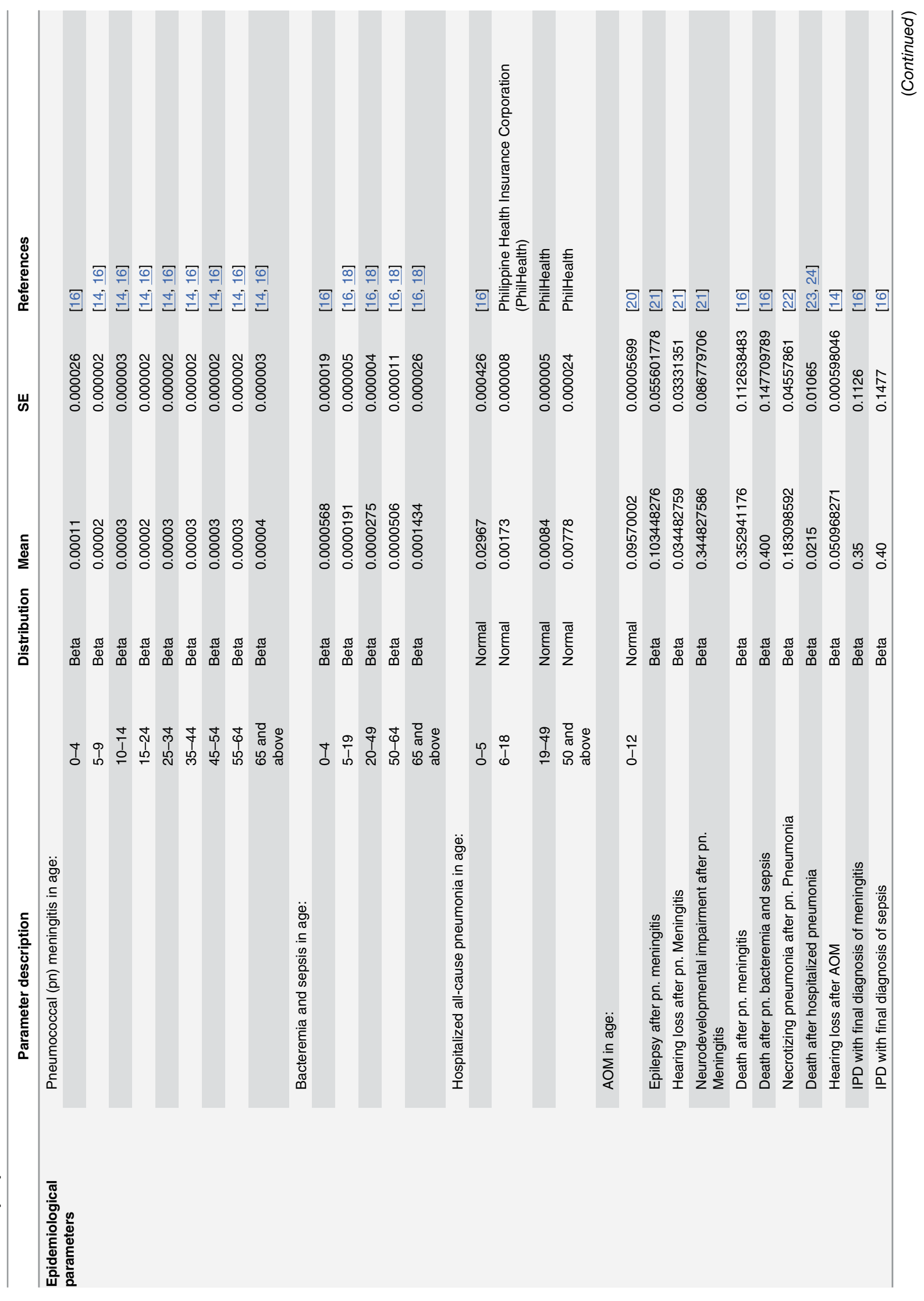




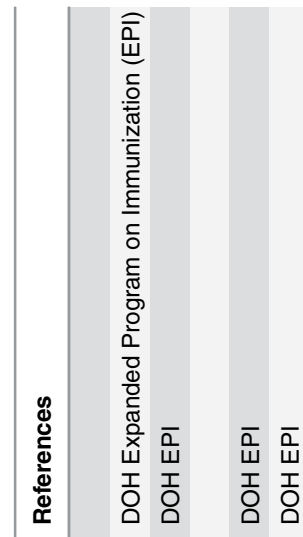

嵓

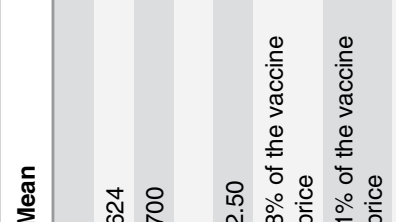

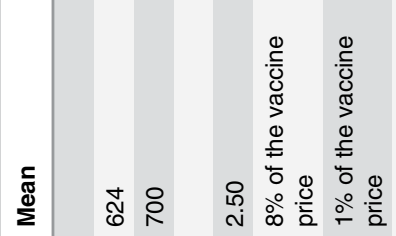
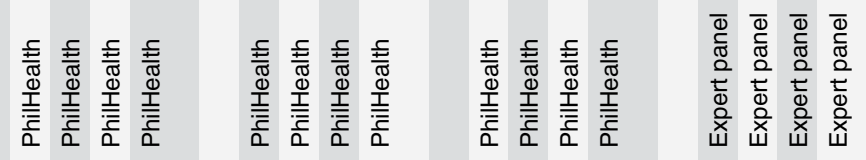

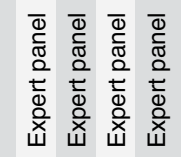

吉导

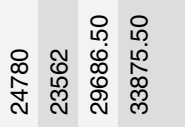

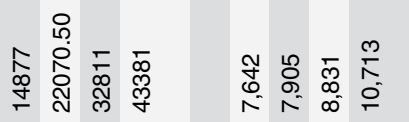

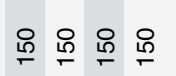

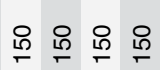

울

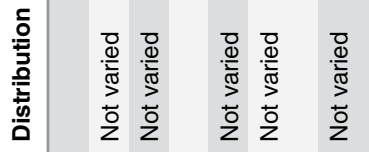

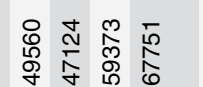

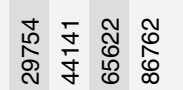

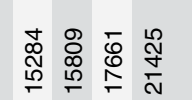

৪্ল

৪্ল

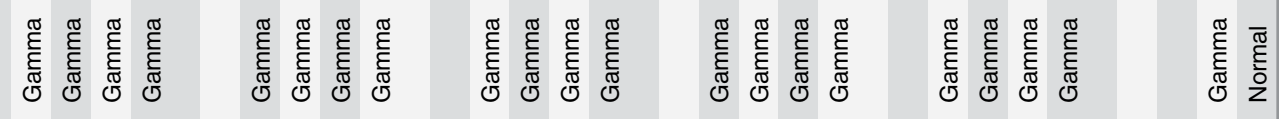

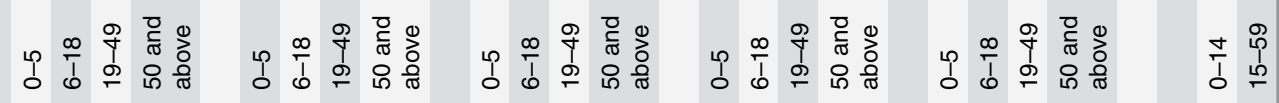

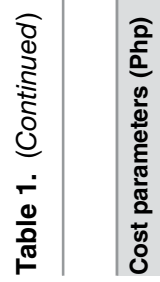




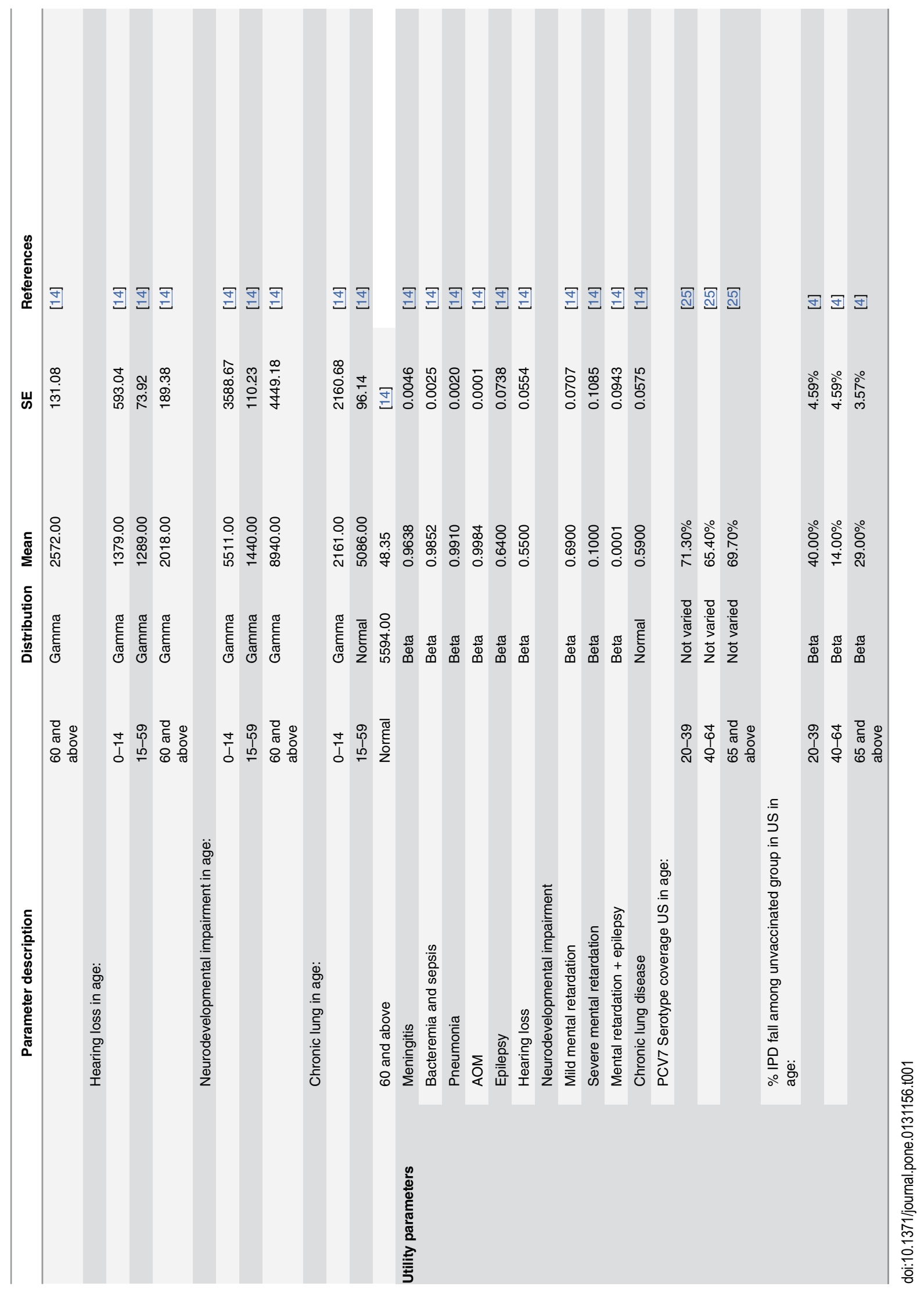




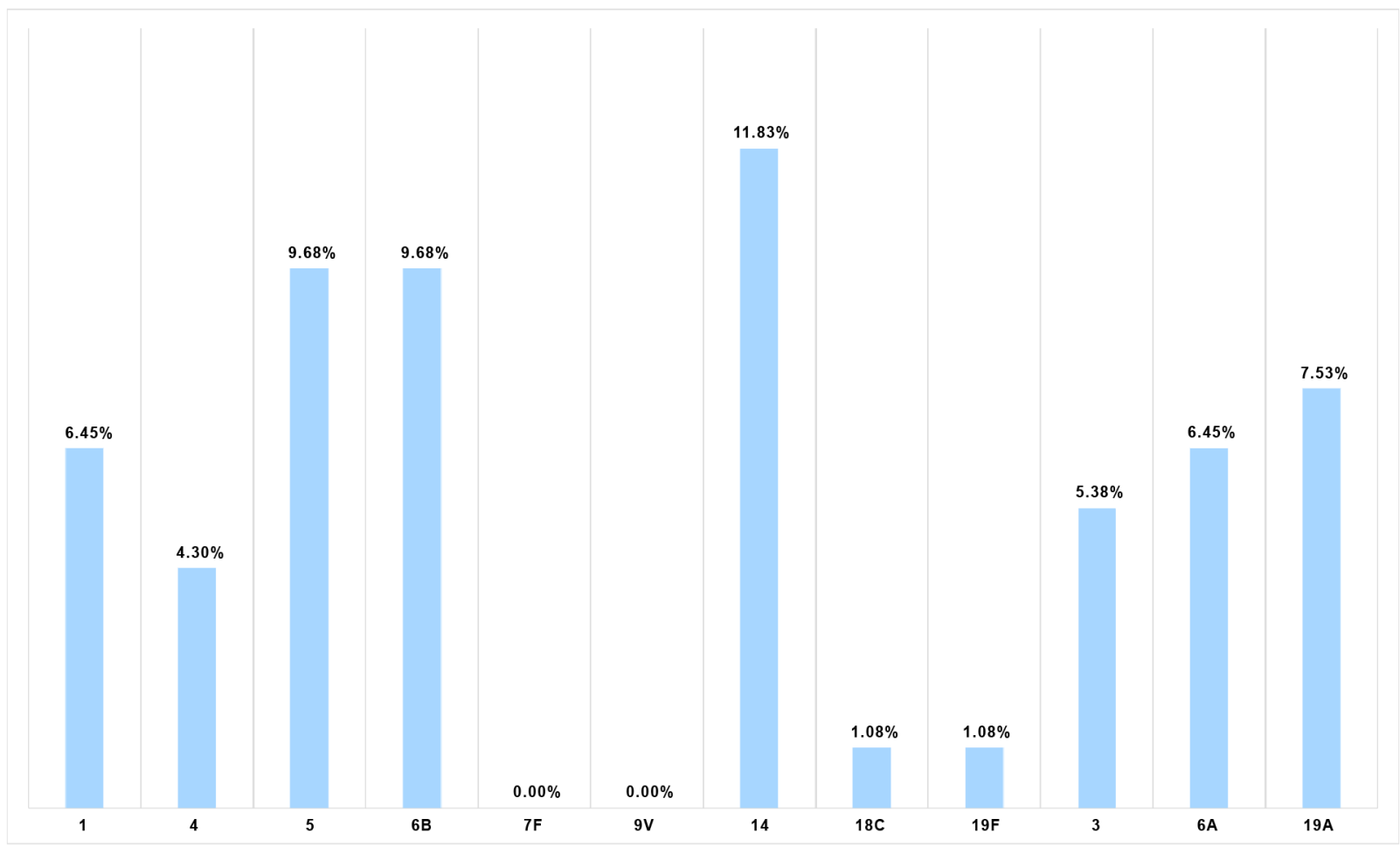

Fig 2. Proportion of IPD serotypes among Filipino children aged $<5$ years covered by $P C V 13(N=93)$.

doi:10.1371/journal.pone.0131156.g002 
Table 2. Vaccine efficacy by syndrome adjusted by $2+1$ schedule and local serotype distribution.

Health conditions

\begin{tabular}{|c|c|c|}
\hline & \\
\hline & PCV10 & PCV13 \\
\hline IPD all serotypes & $46.49 \%^{\mathrm{a}}$ & $64.30 \%{ }^{b}$ \\
\hline Clinical pneumonia & $8.42 \%{ }^{\mathrm{c}}$ & $11.64 \%{ }^{\mathrm{d}}$ \\
\hline Clinical AOM & $18.38 \%{ }^{\mathrm{e}}$ & $25.43 \%{ }^{f}$ \\
\hline \multicolumn{3}{|c|}{ a- $P C V 10_{2+1} V E$ against vaccine type IPD $\times$ local vaccine serotype IPD coverage of PCV10 } \\
\hline \multicolumn{3}{|c|}{ b- $P C V 10_{2+1} V E$ against vaccine type IPD $\times$ local vaccine serotype IPD coverage of PCV13 } \\
\hline \multicolumn{3}{|c|}{ c- $P C V 10_{3+1}$ VE against clinical pneumonia $\times(1-0.0324)$} \\
\hline \multirow{2}{*}{\multicolumn{3}{|c|}{$\begin{array}{l}\text { d- } P C V 10_{3+1} V E \text { against clinical pneumonia } \times(1-0.0324) \\
\text { local vaccine serotype IPD coverage of } P C V 10)\end{array}$}} \\
\hline & & \\
\hline \multicolumn{3}{|c|}{ e- $P C V 10_{3+1} V E$ against clinical $A O M \times(1-0.0324)$} \\
\hline \multicolumn{3}{|c|}{$\begin{array}{l}\mathrm{f}-P C V 10_{3+1} V E \text { against clinical } A O M \times(1-0.0324) \times(\text { local vaccine serotype IPD coverage of } P C V 13 / / o c a l \\
\text { vaccine serotype IPD coverage of } P C V 10)\end{array}$} \\
\hline
\end{tabular}

doi:10.1371/journal.pone.0131156.t002

was used to adjust vaccine efficacy derived from a $3+1$ dosing schedule to a $2+1$ schedule:

$$
V E_{2+1}=V E_{3+1} \times(1-0.0324)
$$

Indirect effects (herd protection). Besides estimating the direct effects of the vaccine, the model also assessed the vaccine's indirect effects against IPD among the unvaccinated population. Herd protection was assumed to be realized at a vaccination coverage rate of $80 \%[38,39]$. The percentage change in IPD infections among unvaccinated individuals was based on the percentage decline of IPD incidence in the United States following the introduction of routine vaccination of PCV7 for infants and young children [4], adjusted for the difference between the USA and the Philippine serotype coverage. Expected IPD percentage reduction for the Philippines and the USA is reflected for different age groups in S2 Table.

This study considered herd protection for pneumococcal meningitis, bacteremia/sepsis, and pneumonia. In order to estimate the percentage change for pneumonia among unvaccinated populations, it was assumed that pneumonia incidence decreases proportionally to the IPD fall for respective age groups, adjusted by the ratio of pneumococcal pneumonia to hospitalized pneumonia cases.

Duration of vaccine protection was assumed to be 5 years for both direct and indirect effects, which is in line with other PCV economic evaluations [40-42].

Vaccine costs. Costs were converted into Philippine peso using the mean exchange rate between the US Dollar and the Philippine peso (Php) in December 2013 (1 USD $=44.20 \mathrm{Php}$ ) [43]. In 2013, the Philippine government was offered to procure PCV10 and PCV13 for Php 624 and Php 700 per dose, respectively, based on 2013 reference prices of the Philippine EPI, while the market price is between $\mathrm{Php} \mathrm{2,261} \mathrm{to} \mathrm{Php} \mathrm{3,670} \mathrm{[44].} \mathrm{Additional} \mathrm{costs} \mathrm{for} \mathrm{syringe,}$ storage, warehousing, delivery and program implementation were considered (Table 1). Taxes, handling fee and freight cost incurred through UNICEF procurement were excluded since the national program is considering local bidding as its mode of procurement.

Individuals vaccinated through PhilHealth coverage received the vaccine (including its administration) free of charge. Only a single-dose vial presentation is currently available for PCV13, whereas PCV10 is available as a single dose and a two-dose vial presentation, with all 
presentations of both vaccines being prequalified by the WHO. The two dose preservative-free presentation of PCV10 is only available through UN procurement; the implementation of this vaccine presentation requires specific training for immunization staff as well as formal postintroduction monitoring [45]. For this analysis, it was assumed that a single-dose vial presentation for both vaccines would be procured. In terms of wastage, $5 \%$ of the total quantity of PCV10 and PCV13 was added according to WHO recommendations on vaccines with single dose presentation.

Other medical costs. Insurance claims data from 2012 were provided by PhilHealth and used to calculate the unit cost of hospitalized bacterial meningitis, hospitalized all-cause pneumonia, hospitalized all-cause sepsis and bacteremia (Table 1). WHO ICD 10 codes were used as reference to extract the total medical cost for each disease presentation.

Each insurance claim reflected both the actual total cost per case and the amount reimbursed by PhilHealth, excluding professional fees and other administration costs. For the base case analysis, the average of the actual total cost of all claims from public hospitals were considered, since PhilHealth reimbursement typically only covers a certain amount of the actual total cost per claim. Public hospital cost figures were adjusted by a 50\% mark-up to account for administration cost, including professional fees in public hospitals (PhilHealth estimate). Private hospital cost significantly exceeded public hospital cost and were not regarded to be a reasonable proxy of actual medical cost. In sensitivity analysis, private hospital costs were taken into account by using a weighted average of public and private hospital costs.

Due to a lack of local studies and considering that the number of claims for relatively rare sequelaes due to $S$. pneumoniae may not be representative of the total number of cases in the country, the cost per year of these conditions were obtained from Thai cost data as presented in the economic evaluation of PCV 10 and 13 in Thai context [14]. 2010 Thai figures and 2012 PhilHealth figures were adjusted to 2013 for inflation and PPP (1 THB = 1.54 PHP), using the EPPI Centre Cost Converter as of 27 January 2014 [46].

Utilities. Due to absence of local utility parameters, Thai values using the Health Utilities Index Mark 3 were adopted [47].

\section{Analysis}

One-way sensitivity analysis was performed to explore the robustness of the results to variations in uncertain key assumptions. The following alternative scenarios were assessed: discount rate at $0 \%$ and $10 \%$ per annum; duration of vaccine protection of 10 years; weighted average of public and private treatment cost based on PhilHealth claims; serotype replacement by using variation in vaccine serotype coverage; exclusion of herd protection; vaccine price using higher market prices; 40:60 ratio of hospitalized to non-hospitalized pneumonia cases; and exclusion of serotype 3 from local serotype coverage of PCV13 due to recent effectiveness data from the UK suggesting that PCV13 may be ineffective against serotype 3 [48].

Probabilistic sensitivity analysis was conducted using the Monte Carlo simulation using Microsoft Office Excel 2007. According to the feasible range of values each parameter could attain, the following probability distributions were used: the beta distribution was the choice of distribution when parameter values ranged between zero to one. The gamma distribution was used when parameter values ranged between zero to infinity, and the normal distribution was used when data were symmetrically distributed. A 1,000 iterations were run to yield possible values for costs, health outcomes and incremental cost-effectiveness ratios (ICERs). Acceptability curves were generated, showing the probability of each intervention being cost-effective at different ceiling threshold values. 
A ceiling threshold of one per capita gross domestic product or Php 120,000 per QALY gained was used to determine the cost-effectiveness of each intervention as recommended by the FEC [49]. Budget impact analysis was performed to forecast the financial impact for a 5-year horizon of implementing PCV for either universal or partial coverage.

\section{Results}

Universal child vaccination with PCV would reduce both the clinical and the economic burden caused by $S$. pneumoniae infection. For an entire vaccinated birth cohort of 2 million infants, the 2+1 dose schedule of PCV10 and PCV13 was estimated to avert 334 and 654 episodes of IPD (meningitis, bacteremia) in the vaccinated population, respectively, compared to no vaccination (Fig 3). Indirect benefits of vaccination among the unvaccinated population, including the elderly, would prevent an additional 1,145 and 1,204 episodes of IPD (meningitis, bacteremia). Furthermore, using PCV10 and PCV13 would avoid 140,107 and 194,782 episodes of $\mathrm{AOM}$, and 26,096 and 34,140 episodes of clinical pneumonia, respectively. In addition, it is estimated that implementing PCV10 and PCV13 would prevent 1,904 and 2,399 deaths, respectively.

Table 3 illustrates the ICERs of a $2+1$ dose schedule of PCV10 and PCV13 for both scenarios. Considering the country-specific threshold of Php 120,000 per QALY gained, vaccinating the entire birth cohort with PCV10 and PCV13 (Scenario 1) would be highly cost-effective, producing ICERs of Php 68,182 and Php 54,510 per QALY gained, respectively, compared to no vaccination. Compared to PCV10, PCV13 generates better outcomes in terms of QALYs, life years gained and deaths averted with an ICER of Php 15,795.

In scenario 2, where indirect effects of vaccination were excluded due to partial vaccination coverage that is fully funded by the government, ICER values of PCV10 (Php 112,640) and PCV13 (Php 84,654) increased significantly, yet were still below the cost-effectiveness threshold of Php 120,000.

In one-way sensitivity analysis for scenario 1 , selected parameters had a significant impact on ICERs, except serotype coverage, treatment cost (weighted average of public and private), and ratio of inpatient to outpatient pneumonia cases (40:60) (Fig 4). Substantial variations in ICER values were obtained with vaccine cost, exclusion of indirect effects, vaccine efficacy, and duration of vaccine protection. The discount rate may be considered as the single most significant parameter affecting the value for money of both vaccines. A small change in the discount rate resulted in a disproportionately larger change in the ICERs. Assuming there is no efficacy of PCV13 against serotype 3, the ICER of PCV13 increased by $11.76 \%$ to Php 60,921.

Fig 5 demonstrates that adopting either universal or partial access to PCV (as compared to no vaccination) offers good value for money for the $\mathrm{DOH}$, given the current ceiling threshold of Php 120,000 per QALY gained. For both scenarios, PCV13 yielded a 100\% probability of being cost-effective compared to no vaccination and to PCV10 at the given ceiling threshold.

Threshold analysis revealed that in scenario 1, PCV10 and PCV13 prices would have to be $79 \%$ and 76\% lower (to Php 131 and Php 166) in order to be cost-saving (ICER $=0$ ) for the Philippines. In scenarios 2, the maximum vaccine costs for PCV10 and PCV13 would have to range from Php 42 to Php 60, respectively.

Table 4 presents the 5-year budget impact of implementing PCV10 and PCV13 for scenarios 1 and 2. Including PCV10 and PCV13 in the EPI for nationwide coverage requires an additional budget of Php 18.37 billion (US\$ 416 million) and Php 20.41 billion (US\$ 462 million), respectively, compared to no vaccination. Implementing PCV10 and PCV13 for only $25 \%$ of the birth cohort would require additional costs of Php 4.59 billion (US\$ 104 million) and Php 

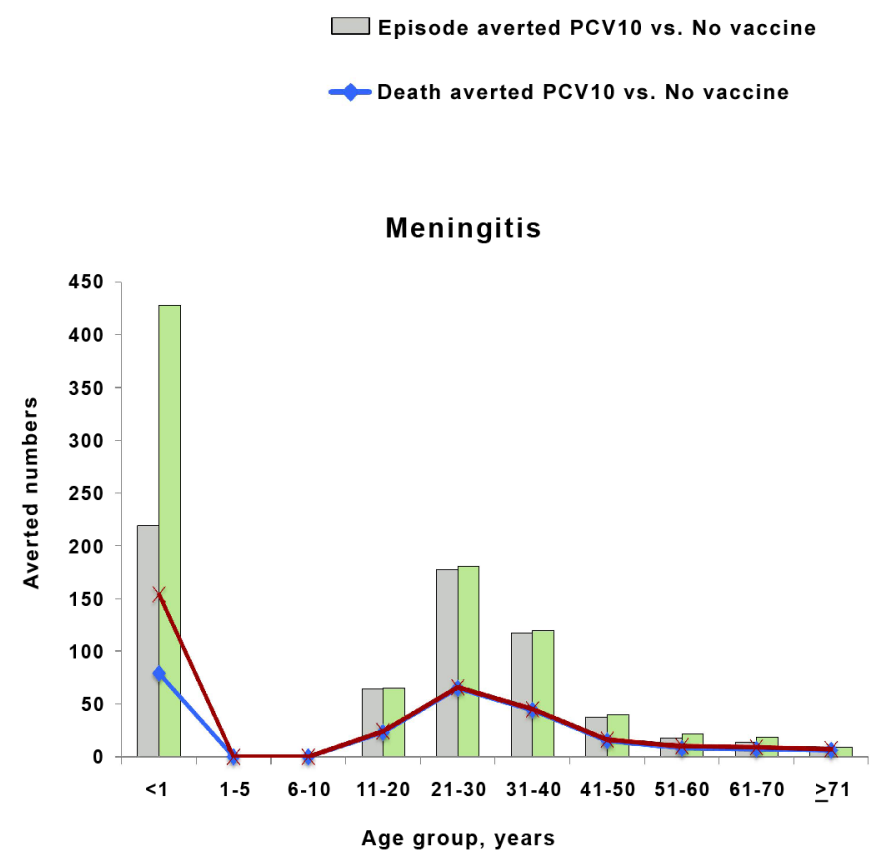

Pneumonia

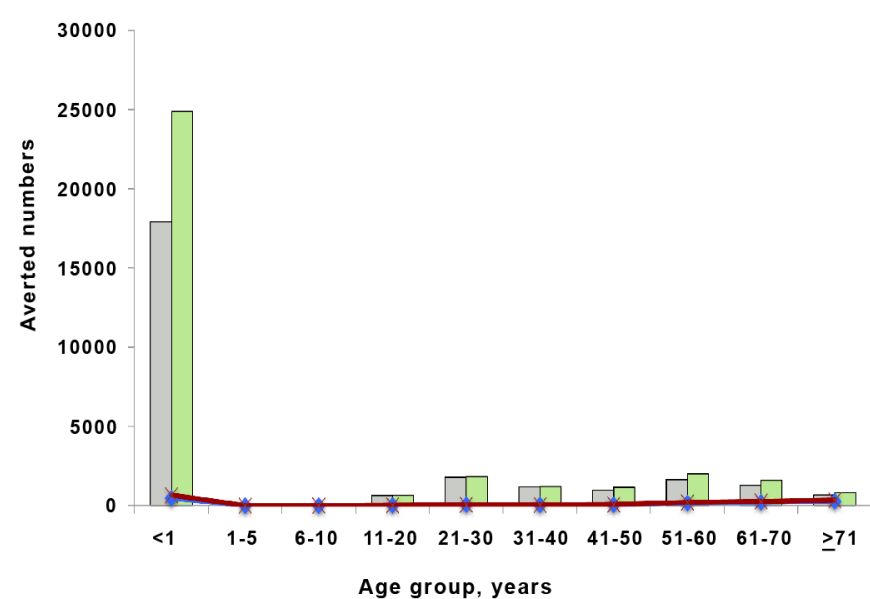

$\square$ Episode averted PCV13 vs. No vaccine

¿ Death averted PCV13 vs. No vaccine

Bacteremia and Sepsis

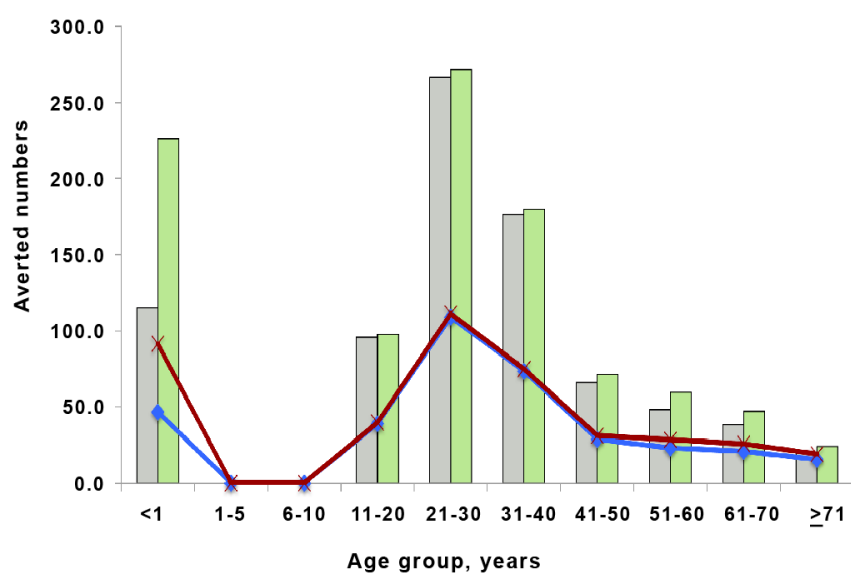

AOM

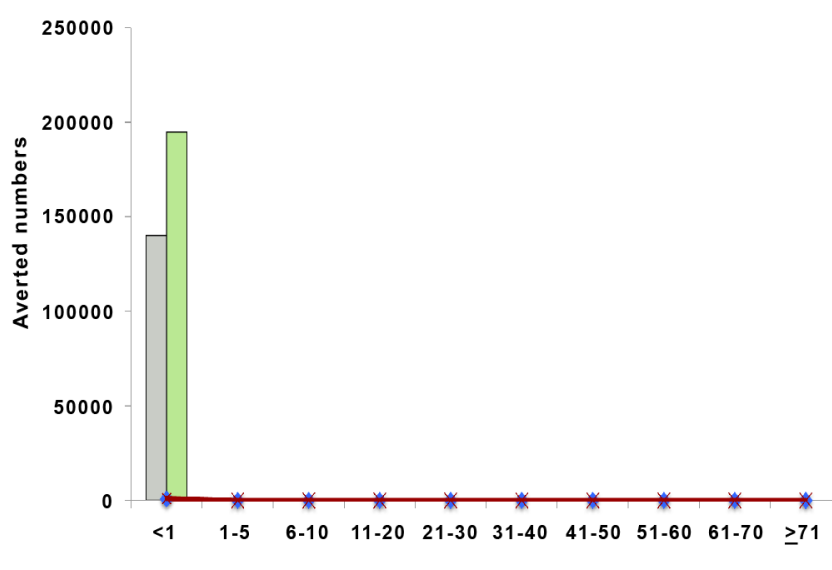

Age group, years

Fig 3. Predicted numbers of life-time pneumococcal disease cases and deaths averted due to vaccination with PCV10 and PCV13 by clinical syndrome and age at entry to the cohort.

doi:10.1371/journal.pone.0131156.g003

5.11 billion (US\$ 116 million), with fixed treatment costs of Php 30.98 billion (US\$ 701 million) if no vaccination is introduced.

\section{Discussion}

This study is the first economic evaluation conducted in the Philippines and to our best knowledge, it is the first in the world conducted after the release of the newest clinical evidence on 
Table 3. Incremental outcomes of introducing PCV10 and PCV13 compared to no vaccination.

\begin{tabular}{|c|c|c|c|c|c|c|c|c|c|c|c|c|}
\hline & \multicolumn{4}{|c|}{ PCV 10 vs. no vaccination } & \multicolumn{4}{|c|}{ PCV 13 vs. no vaccination } & \multicolumn{4}{|c|}{ PCV 13 vs. PCV 10} \\
\hline & $\begin{array}{l}\text { Inc. } \\
\text { Cost }\end{array}$ & Inc. LYs & $\begin{array}{l}\text { Inc. } \\
\text { QALYs }\end{array}$ & $\begin{array}{l}\text { ICER/ } \\
\text { QALY } \\
\text { (Php) }\end{array}$ & $\begin{array}{l}\text { Inc. } \\
\text { Cost }\end{array}$ & Inc. LYs & $\begin{array}{l}\text { Inc. } \\
\text { QALYs }\end{array}$ & $\begin{array}{l}\text { ICER/ } \\
\text { QALY } \\
\text { (Php) }\end{array}$ & $\begin{array}{l}\text { Inc. } \\
\text { Cost }\end{array}$ & Inc. LYs & $\begin{array}{l}\text { Inc. } \\
\text { QALYs }\end{array}$ & $\begin{array}{l}\text { ICER/ } \\
\text { QALY } \\
\text { (Php) }\end{array}$ \\
\hline $\begin{array}{l}\text { With herd } \\
\text { protection } \\
\text { Scenario } 1 \\
\text { (Universal } \\
\text { coverage) }\end{array}$ & 1491 & 0.01174 & 0.02186 & 68,182 & 1613 & 0.015222 & 0.029584 & 54,510 & 122 & 0.003482 & 0.007724 & 15,795 \\
\hline $\begin{array}{l}\text { Without herd } \\
\text { protection } \\
\text { Scenario } 2(25 / 0)\end{array}$ & 440 & 0.001418 & 0.003906 & 112,640 & 483 & 0.00217 & 0.00571 & 84,654 & 43 & 0.000752 & 0.001804 & 23,836 \\
\hline
\end{tabular}

LY- life years

QALY- Quality adjusted life year

doi:10.1371/journal.pone.0131156.t003

efficacy of PCV10 published in 2014 [13]. It shows that at current vaccine pricing and ceiling threshold, introducing universal vaccination with either PCV10 or PCV13 would be cost-effective, compared to no vaccination. Introducing universal PCV vaccination throughout the country would cost Php 3.87-4.34 billion annually, or 1.6 to 1.8 times the budget currently allocated for the EPI. Hence, universal vaccination will only be feasible if additional budget for the EPI program is allocated, or vaccine prices are lowered. The current allocated budget of the NIP would suffice to vaccinate only $25 \%$ of the birth cohort.

Considering between the two vaccines, this study indicates that PCV13 achieves better value for money compared to PCV10, thus, PCV13 should be a better choice in the Philippines. The model was very sensitive to vaccine price and indirect effects (herd protection). However, while the use of current market prices for PCV10 and PCV13 made vaccination cost-ineffective, excluding herd protection generated ICER values that remained below the country-specific threshold. Excluding serotype 3 from the serotype coverage of PCV13 generated an ICER still below the base case ICER of PCV10. Apart from economic reasons, PCV13 is superior to PCV10 in terms of its broader coverage of serotypes; a universal vaccination program with PCV13 would lower the potential for serotype replacement. This phenomenon has been experienced in many countries including the USA and UK, where a dramatic increase in IPD caused by non-vaccine serotypes following PCV7 introduction offset some of the benefits of vaccination $[5,50]$. Serotype replacement was particularly observed for the multi-resistant serotype 19A [51-53], which is only covered by PCV13. As a consequence, many Western countries replaced the earlier version of PCV7 with PCV13 in their national immunization programs due to the rapid rise of this virulent serotype in invasive pneumococcal isolates [54]. Serotype 19A was also one of the more commonly isolated serotypes in Filipino children under 5 years of age [27]. A case-control study of PCV7 effectiveness and studies comparing immunogenicity of PCV10 and PCV7 suggest a potential cross-reactivity effect of PCV10 against serotypes 6A and 19A, due to the contained antigens in PCV10 against serotype 6B and 19F [55, 56]. However, cross-reactivity results of PCV10 based on the COMPAS were not significant (cross-reactive serotypes IPD [6A, 9N, or 19A] -99.5\% \{95\% CI: -2,100.2-81.9\} and AOM [6A, 18B, 19A, or $23 \mathrm{~A}] 29 \%$ \{95\% CI: $-123.7-77.5\}$ ) [13], cross-protection was therefore not considered in the model.

This cost-effectiveness study used a similar analytic approach to that used in Thailand [14], in terms of the static model structure and utility values considered, and methods used to derive 


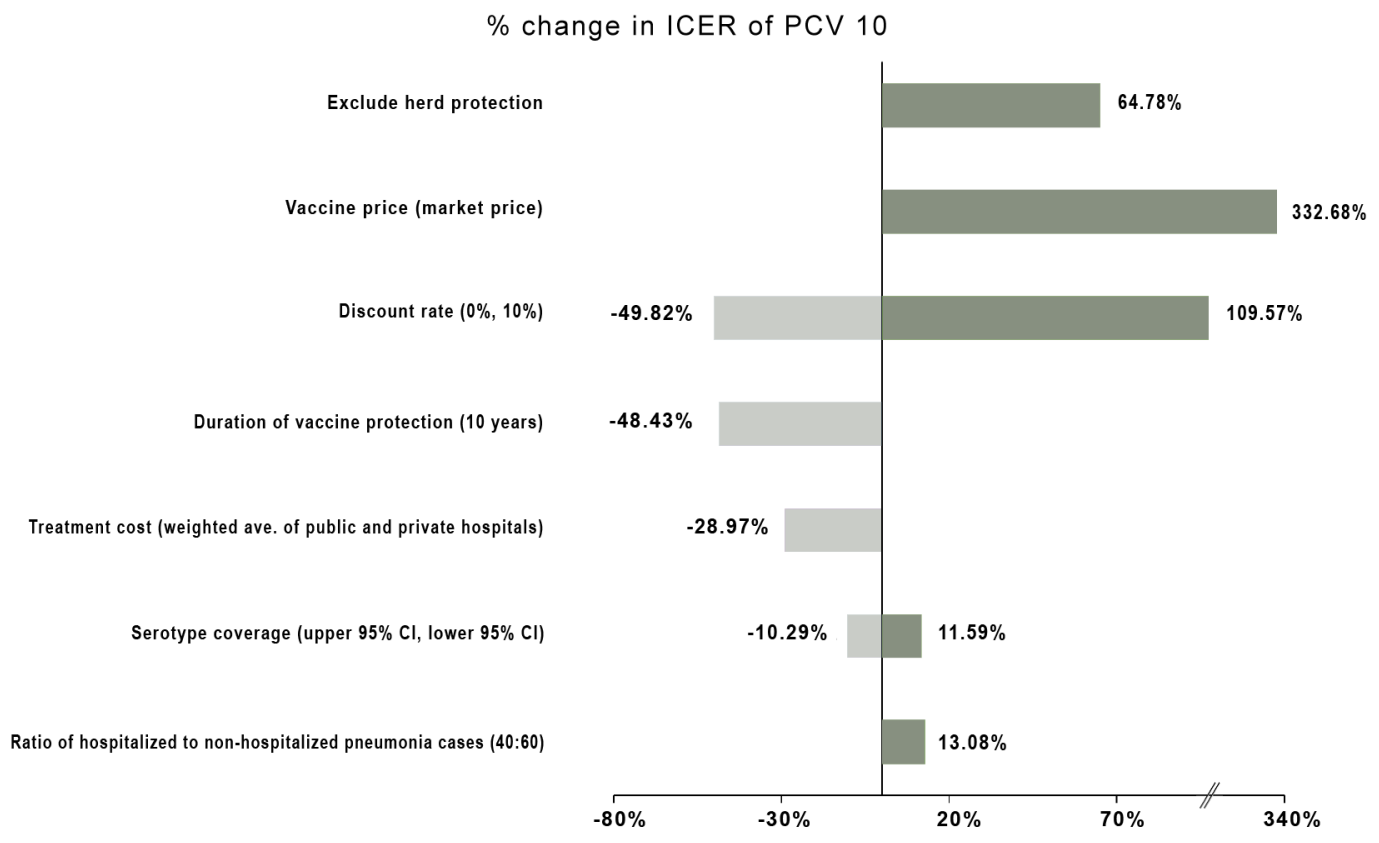

\% change in ICER of PCV 13

Exclude herd protection

Vaccine price (market price)

Discount rate $(0 \%, 10 \%)$

Duration of vaccine protection (10 years)

Treatment cost (weighted ave. of public and private hospitals)

Serotype coverage (upper $95 \%, \mathrm{Cl}$, lower $95 \% \mathrm{Cl}$ )

Ratio of hospitalized to non-hospitalized pneumonia cases $(40: 60)$

Excluding serotype 3

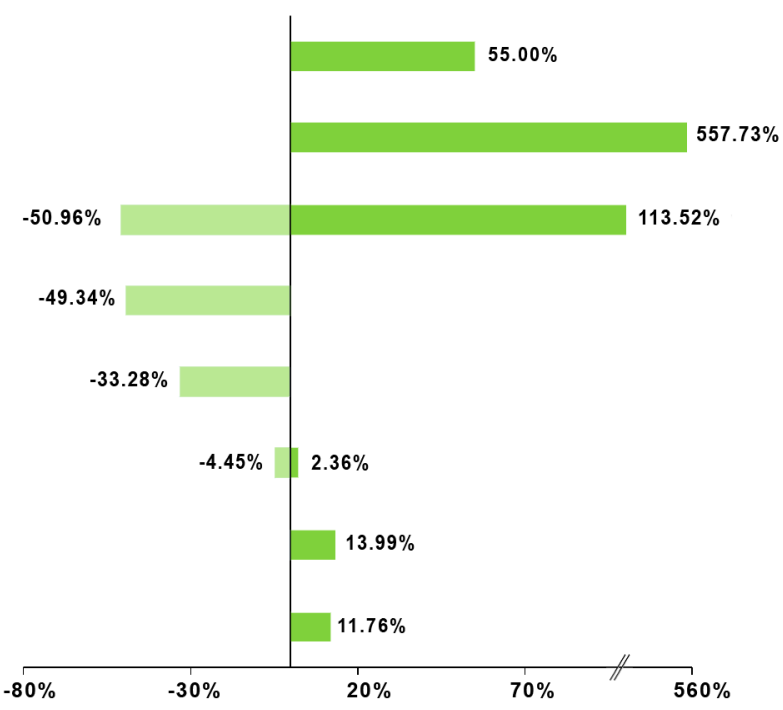

Fig 4. Tornado diagram for PCV10 and PCV13 versus no vaccination. Exploring the impact of uncertainty in key model parameters on ICERs of PCV10 (Php 68,182) and PCV13 (Php 54,510) in the scenario of universal coverage.

doi:10.1371/journal.pone.0131156.g004

vaccine efficacy and indirect effects. However, in contrast to the Philippines' findings, Thai results showed that neither PCV10 nor PCV13 were cost-effective at the ceiling threshold of THB 100,000 (US\$3,226). The differences may be explained by differences in vaccine price, epidemiological parameters, and vaccine efficacy used in the model. Thai government vaccine prices per dose were significantly higher (THB 1,440 or US 46 for PCV10 and THB 1,930 or US 62 for PCV13), whereas Thai IPD incidence, mortality rates, and AOM efficacy values were lower. Results of this study are similar to previous studies conducted in Taiwan and 
$\diamond$ No vaccine $\prec$ PCV $10 \prec$ PCV 13

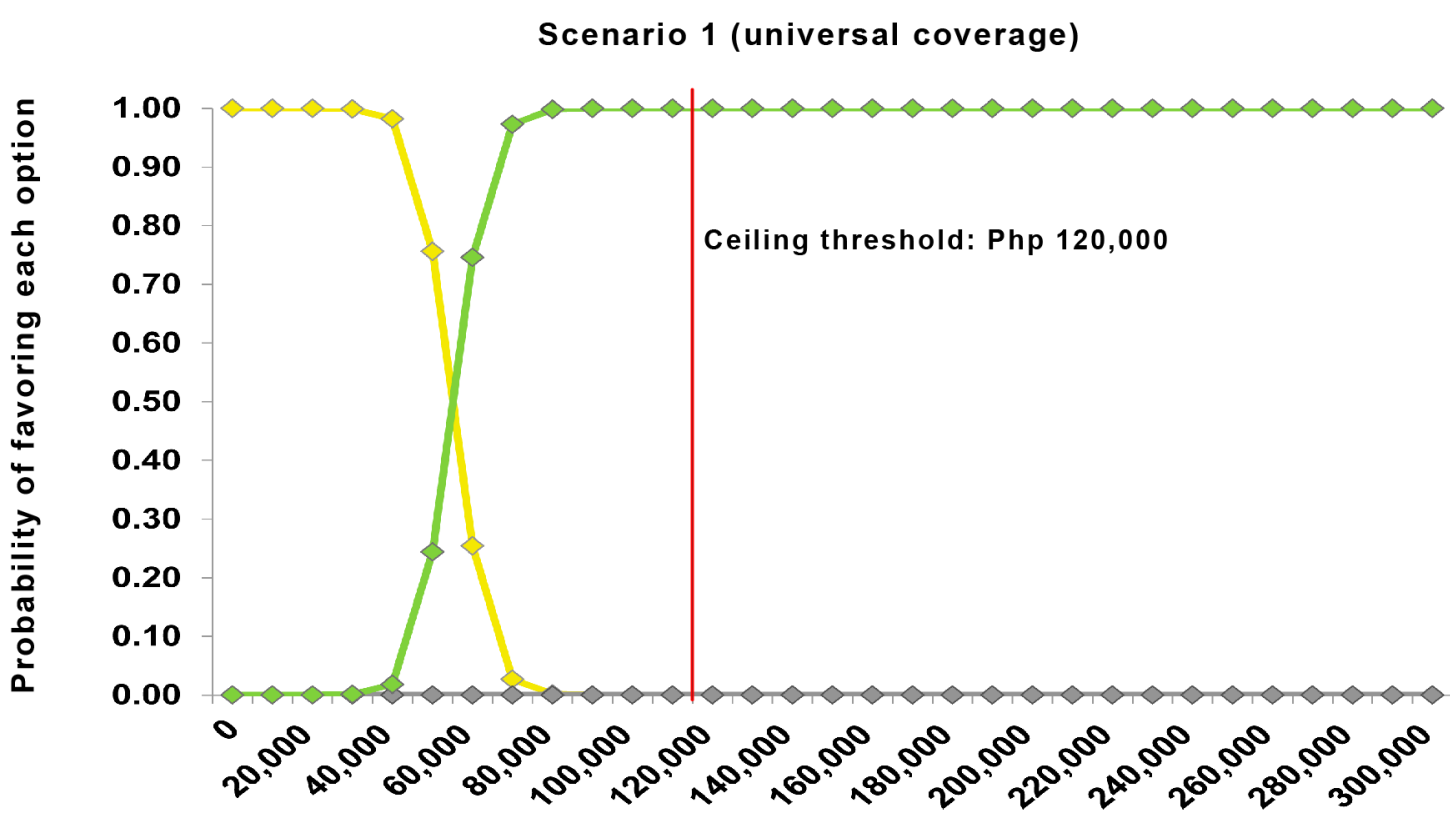

Value of ceiling ratio (Php per QALY)

Scenario 2 (partial coverage)

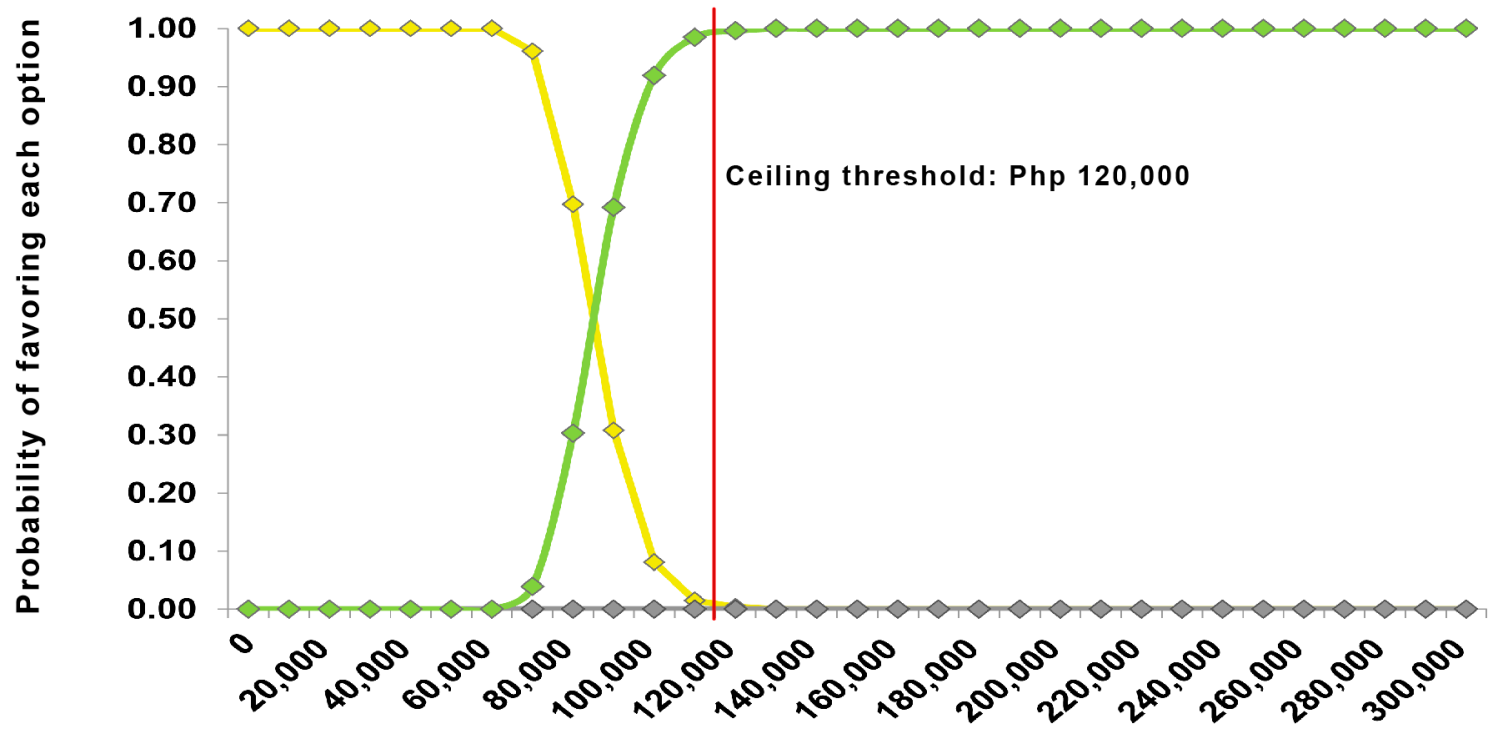

Value of ceiling ratio (Php per QALY)

Fig 5. Cost-effectiveness acceptability curves for PCV10, PCV13 and no vaccination in the scenarios of universal and partial coverage.

doi:10.1371/journal.pone.0131156.g005

Singapore, which found PCV13 to be cost-effective [9, 11, 42]. In Singapore, pneumococcal conjugate vaccination was a cost-effective intervention only if herd protection effects were considered, resulting in ICER values comparable to the country's GDP per capita. The cost per 
Table 4. Budget impact analysis of scenario 1 and 3 compared to no vaccination in billions (Php).

\begin{tabular}{|c|c|c|c|c|c|c|c|c|c|}
\hline & \multicolumn{4}{|c|}{ Scenario 1 (Universal vaccination coverage) } & \multicolumn{4}{|c|}{ Scenario 2 (25\% vaccination coverage) } & \multirow{3}{*}{$\begin{array}{l}\text { No } \\
\text { Vaccination } \\
\text { Program } \\
\\
\begin{array}{l}\text { Treatment } \\
\text { cost }\end{array}\end{array}$} \\
\hline & \multicolumn{2}{|c|}{ PCV 10} & \multicolumn{2}{|c|}{ PCV 13} & \multicolumn{2}{|c|}{ PCV 10} & \multicolumn{2}{|c|}{ PCV 13} & \\
\hline & $\begin{array}{l}\text { Vaccination } \\
\text { cost }\end{array}$ & $\begin{array}{l}\text { Treatment } \\
\text { cost }\end{array}$ & $\begin{array}{l}\text { Vaccination } \\
\text { cost }\end{array}$ & $\begin{array}{l}\text { Treatment } \\
\text { cost }\end{array}$ & $\begin{array}{l}\text { Vaccination } \\
\text { cost }\end{array}$ & $\begin{array}{l}\text { Treatment } \\
\text { cost }\end{array}$ & $\begin{array}{l}\text { Vaccination } \\
\text { cost }\end{array}$ & $\begin{array}{l}\text { Treatment } \\
\text { cost }\end{array}$ & \\
\hline Year 1 & 3.87 & 6.34 & 4.34 & 6.32 & 0.97 & 6.43 & 1.09 & 6.42 & 6.45 \\
\hline Year 2 & 3.87 & 5.87 & 4.34 & 5.83 & 0.97 & 5.99 & 1.09 & 5.97 & 6.02 \\
\hline Year 3 & 3.87 & 5.92 & 4.34 & 5.86 & 0.97 & 6.06 & 1.09 & 6.05 & 6.11 \\
\hline Year 4 & 3.87 & 5.93 & 4.34 & 5.84 & 0.97 & 6.10 & 1.09 & 6.08 & 6.17 \\
\hline Year 5 & 3.87 & 5.94 & 4.34 & 5.84 & 0.97 & 6.14 & 1.09 & 6.12 & 6.23 \\
\hline $\begin{array}{l}5 \text { year } \\
\text { Budget } \\
\text { Impact }\end{array}$ & 19.35 & 30.00 & 21.70 & 29.69 & 4.85 & 30.72 & 5.45 & 30.64 & 30.98 \\
\hline $\begin{array}{l}\text { Total Budget } \\
\text { Impact }\end{array}$ & 49.35 & & 51.39 & & 35.57 & & 36.09 & & 30.98 \\
\hline $\begin{array}{l}\text { Incremental } \\
\text { Budget }\end{array}$ & 18.37 & & 20.41 & & 4.59 & & 5.11 & & \\
\hline
\end{tabular}

doi:10.1371/journal.pone.0131156.t004

QALY of PCV13 was lower compared to PCV10; however, if PCV10 was attributed a protective effect against NTHi AOM, it was found to be more cost-effective compared to PCV13.

This study has some limitations. First, due to lacking clinical trial data against final clinical endpoints, vaccine efficacy for PCV13 was extrapolated from PCV10 efficacy trials, which may under- or overestimate its efficacy. Second, this study did not employ dynamic modeling, which is generally recommended by cost-effectiveness analysis guidelines in order to account for externalities. However, this study used an excel-based static model (Markov), which accounted for indirect effects of vaccination. The use of static model facilitated transparency in terms of the methods used in this study because many local decision makers are familiar with this type of modeling. Third, since no local data on indirect vaccine effects were available, US data were used and adjusted to local serotype coverage. However, US findings showed a statistically significant decline in IPD incidence among unvaccinated persons aged 20 years and above only. Thus, our study did not include indirect effects among populations under 20 years. Fourth, the only available study on IPD incidence in the country was hospital-based [16], with incidences weighted by the number of children in the at-risk population, which may have led to an overestimation of IPD incidence rates used in the model. On the contrary, lower bacterial isolation rates attributed to high rates of antimicrobial use by parents of young children in the Philippines may have led to an underestimation of IPD [16]. Fifth, results of this study are dependent on the local serotype distribution and on the country-specific ceiling threshold, with the latter being based on the preferences of decision makers in the Philippines. Therefore, applying results of this study to other settings or populations should be performed with caution. Sixth, we assumed all AOM cases are treated on an outpatient basis, resulting in an underestimation of the cost of AOM treatment because in some severe cases, hospitalization for tube replacement may be required. However, including hospitalization cost for AOM will not change our overall conclusion as higher treatment cost will result in a lowering of the ICERs, which will further favor vaccination. Lastly, differences in pathogenicity between pneumococcal serotypes are important when evaluating the benefits of pneumococcal conjugate vaccines of different valency [57]. This model did not account for differences between serotypes in terms of their propensity to cause morbidity or death. 


\section{Supporting Information}

S1 Table. Philippine vaccine-type IPD coverage of PCV7, PCV10, and PCV13 in different age groups.

(DOCX)

S2 Table. Summary of \% reduction in IPD and Pneumonia incidences in the Philippines (PHL) based on US data.

(DOCX)

\section{Acknowledgments}

The authors express their gratitude to NICE International Director Kalipso Chalkidou and Senior Advisor Francis Ruiz for their technical support and helpful comments during the revision of the manuscript. We would also like to thank Dr. Anna Melissa Guerrero, Dr. Cecilia Maramba-Lazarte, Dr. Maria Joyce Ducusin, Engr. Luzviminda Garcia, Kuntika Dumrongprat, Thanaporn Bussabawalai, Sarocha Chootipongchaivat, Thanthima Suwanthawornkul, Dr. Gloria Nenita Velasco, Dr. Irene Fariñas, and Ermalyn Magturo for their contribution in developing this manuscript as well as other decision makers led by former Undersecretary of Health Madeleine de Rosas-Valera and other stakeholders who participated in expert consultation meetings for invaluable discussions about the reliability and validity of findings and recommendations. We also wish to acknowledge the contribution of the Philippine Health Insurance Corporation and Dr. Maria Rosario Capeding from the Research Institute for Tropical Medicine (RITM) for providing data and reference materials used in the analysis.

\section{Author Contributions}

Analyzed the data: MAH JAC WK YT MA. Contributed reagents/materials/analysis tools: YT WK. Wrote the paper: MAH JAC WK YT.

\section{References}

1. Black S, Shinefield H, Fireman B, Lewis E, Ray P, Hansen JR, et al. Efficacy, safety and immunogenicity of heptavalent pneumococcal conjugate vaccine in children. The Pediatric infectious disease journal. 2000; 19(3):187-95. PMID: 10749457

2. Black SB, Shinefield HR, Ling S, Hansen J, Fireman B, Spring D, et al. Effectiveness of heptavalent pneumococcal conjugate vaccine in children younger than five years of age for prevention of pneumonia. The Pediatric infectious disease journal. 2002; 21(9):810-5. PMID: 12352800

3. Eskola J, Kilpi T, Palmu A, Jokinen J, Eerola M, Haapakoski J, et al. Efficacy of a pneumococcal conjugate vaccine against acute otitis media. New England Journal of Medicine. 2001; 344(6):403-9. PMID: 11172176

4. Whitney CG, Farley MM, Hadler J, Harrison LH, Bennett NM, Lynfield R, et al. Decline in invasive pneumococcal disease after the introduction of protein-polysaccharide conjugate vaccine. New England Journal of Medicine. 2003; 348(18):1737-46. PMID: 12724479

5. Miller E, Andrews NJ, Waight PA, Slack MP, George RC. Herd immunity and serotype replacement 4 years after seven-valent pneumococcal conjugate vaccination in England and Wales: an observational cohort study. The Lancet infectious diseases. 2011; 11(10):760-8. doi: 10.1016/S1473-3099(11) 70090-1 PMID: 21621466

6. Philippine Statistics Authority National Statistics Office. Population by Age Group, by Sex and by Region: 2010. 2010.

7. Castañeda-Orjuela C, Alvis-Guzmán N, Velandia-González M, De la Hoz-Restrepo F. Cost-effectiveness of pneumococcal conjugate vaccines of 7,10 , and 13 valences in Colombian children. Vaccine. 2012; 30(11):1936-43. doi: 10.1016/j.vaccine.2012.01.031 PMID: 22266291

8. Chuck AW, Jacobs P, Tyrrell G, Kellner JD. Pharmacoeconomic evaluation of 10-and 13-valent pneumococcal conjugate vaccines. Vaccine. 2010; 28(33):5485-90. doi: 10.1016/j.vaccine.2010.05.058 PMID: 20554066 
9. Urueña A, Pippo T, Betelu MS, Virgilio F, Giglio N, Gentile A, et al. Cost-effectiveness analysis of the 10-and 13-valent pneumococcal conjugate vaccines in Argentina. Vaccine. 2011; 29(31):4963-72. doi: 10.1016/j.vaccine.2011.04.111 PMID: 21621575

10. Rozenbaum MH, Sanders EA, van Hoek AJ, Jansen AG, van der Ende A, van den Dobbelsteen G, et al. Cost effectiveness of pneumococcal vaccination among Dutch infants: economic analysis of the seven valent pneumococcal conjugated vaccine and forecast for the 10 valent and 13 valent vaccines. BMJ. 2010;340.

11. Tyo KR, Rosen MM, Zeng W, Yap M, Pwee KH, Ang LW, et al. Cost-effectiveness of conjugate pneumococcal vaccination in Singapore: comparing estimates for 7-valent, 10-valent, and 13-valent vaccines. Vaccine. 2011; 29(38):6686-94. doi: 10.1016/j.vaccine.2011.06.091 PMID: 21745516

12. Jansen AG, Hak E, Veenhoven RH, Damoiseaux RA, Schilder AG, Sanders EA. Pneumococcal conjugate vaccines for preventing otitis media. The Cochrane database of systematic reviews. 2009;(2: ): Cd001480. Epub 2009/04/17. doi: 10.1002/14651858.CD001480.pub3 PMID: 19370566.

13. Tregnaghi MW, Sáez-Llorens X, López $P$, Abate H, Smith E, Pósleman A, et al. Efficacy of Pneumococcal Nontypable Haemophilus influenzae Protein D Conjugate Vaccine (PHiD-CV) in Young Latin American Children: A Double-Blind Randomized Controlled Trial. PLoS medicine. 2014; 11(6):e1001657. doi: 10.1371/journal.pmed.1001657 PMID: 24892763

14. Kulpeng W, Leelahavarong $P$, Rattanavipapong W, Sornsrivichai $V$, Baggett $H C$, Meeyai $A$, et al. Costutility analysis of 10-and 13-valent pneumococcal conjugate vaccines: Protection at what price in the Thai context? Vaccine. 2013; 31(26):2839-47. doi: 10.1016/j.vaccine.2013.03.047 PMID: 23588084

15. Department of Health Philippines. Vaccine coverage database, Family Health Office (FHO) Expanded Program on Immunization (EPI). 2014.

16. Capeding MR, Bravo L, Santos J, Kilgore PE, Kim SA, Balter I, et al. Prospective Surveillance Study of Invasive Pneumococcal Disease Among Urban Children in the Philippines. The Pediatric infectious disease journal. 2013; 32(10):e383-e9. doi: 10.1097/INF.0b013e318298dfd5 PMID: 23629024

17. Chomchai C, Kim S, Kriengsoonthornkij W, Sutchritpongsa S, Manaboriboon B, Ungcharoen R, editors. Active hospital-based epidemiologic surveillance for invasive pneumococcal disease and pneumonia burden in children in Bangkok, Thailand. Abstract of the 5th Asian Congress of Pediatric Infectious Disease: Sep; 2010.

18. Rhodes J, Hyder JA, Peruski LF, Fisher C, Jorakate P, Kaewpan A, et al. Antibiotic use in Thailand: quantifying impact on blood culture yield and estimates of pneumococcal bacteremia incidence. The American journal of tropical medicine and hygiene. 2010; 83(2):301-6. doi: 10.4269/ajtmh.2010.090584 PMID: 20682872

19. Central Office for Health Information. Data Structure of Inpatient 2006-2010. Bangkok, Thailand. 2011.

20. Caro RM, Llanes EGDV, Ricalde RC. Prevalence of clinically diagnosed acute otitis media (AOM) in the Philippines: a national survey. WSPID; Melbourne, Australia: Otorhinolaryngology, University of the Philippines College of Medicine-Philippine General Hospital, Manila, Philippines; 2011.

21. Netsawang S, Punpanich W, Treeratweeraphong V, Chotpitayasunondh T. Invasive pneumococcal infection in urban Thai children: a 10-year review. Journal of the Medical Association of Thailand = Chotmaihet thangphaet. 2010; 93 Suppl 5:S6-12. Epub 2011/02/08. PMID: 21298830.

22. Hsieh YC, Hsueh PR, Lu CY, Lee PI, Lee CY, Huang LM. Clinical manifestations and molecular epidemiology of necrotizing pneumonia and empyema caused by Streptococcus pneumoniae in children in Taiwan. Clinical infectious diseases: an official publication of the Infectious Diseases Society of America. 2004; 38(6):830-5. Epub 2004/03/05. doi: 10.1086/381974 PMID: 14999627.

23. Tan CC, Ong-Mateo M. Management of community-acquired pneumonia in a university hospital: Adherence to recommended practice guidelines. Santo Tomas Journal of Medicine. 2006; 53(2):37-44.

24. World Health Organization. WHO Global Burden of Disease estimates from 1980-2005 for the Western Pacific Region. In: Expanded Program on Immunization, editor. 2009.

25. Lloyd A, Patel N, Scott DA, Runge C, Claes C, Rose M. Cost-effectiveness of vnheptavalent conjugate pneumococcal vaccine (Prevenar) in Germany: considering a high-risk population and herd immunity effects. The European journal of health economics: HEPAC: health economics in prevention and care. 2008; 9(1):7-15. Epub 2007/03/03. doi: 10.1007/s10198-006-0013-6 PMID: 17333089.

26. Monasta L, Ronfani L, Marchetti F, Montico M, Brumatti LV, Bavcar A, et al. Burden of disease caused by otitis media: systematic review and global estimates. PLoS One. 2012; 7(4):e36226. doi: 10.1371/ journal.pone.0036226 PMID: 22558393

27. Capeding MR. Laboratory-based surveillance of Streptococcus pneumoniae in tertiary health care centers in the Philippines, preliminary report. Research Institute for Tropical Medicine (RITM), 2012.

28. Kieninger DM, Kueper K, Steul K, Juergens C, Ahlers N, Baker S, et al. Safety, tolerability, and immunologic noninferiority of a 13-valent pneumococcal conjugate vaccine compared to a 7 -valent 
pneumococcal conjugate vaccine given with routine pediatric vaccinations in Germany. Vaccine. 2010; 28(25):4192-203. doi: 10.1016/j.vaccine.2010.04.008 PMID: 20417262

29. Esposito S, Tansey S, Thompson A, Razmpour A, Liang J, Jones TR, et al. Safety and immunogenicity of a 13-valent pneumococcal conjugate vaccine compared to those of a 7-valent pneumococcal conjugate vaccine given as a three-dose series with routine vaccines in healthy infants and toddlers. Clinical and vaccine immunology. 2010; 17(6):1017-26. doi: 10.1128/CVI.00062-10 PMID: 20427630

30. Ben-Shimol S, Givon-Lavi N, Leibovitz E, Raiz S, Greenberg D, Dagan R. Near-Elimination of Otitis Media Caused by 13-Valent Pneumococcal Conjugate Vaccine (PCV) Serotypes in Southern Israel Shortly After Sequential Introduction of 7-Valent/13-Valent PCV. Clinical infectious diseases: an official publication of the Infectious Diseases Society of America. 2014; 59(12):1724-32. Epub 2014/08/28. doi: 10.1093/cid/ciu683 PMID: 25159581.

31. Ben-Shimol S, Greenberg D, Givon-Lavi N, Schlesinger Y, Somekh E, Aviner S, et al. Early impact of sequential introduction of 7-valent and 13-valent pneumococcal conjugate vaccine on IPD in Israeli children < 5 years: an active prospective nationwide surveillance. Vaccine. 2014; 32(27):3452-9. Epub 2014/04/03. doi: 10.1016/j.vaccine.2014.03.065 PMID: 24690148.

32. Kaplan SL, Barson WJ, Lin PL, Romero JR, Bradley JS, Tan TQ, et al. Early trends for invasive pneumococcal infections in children after the introduction of the 13-valent pneumococcal conjugate vaccine. The Pediatric infectious disease journal. 2013; 32(3):203-7. Epub 2013/04/06. doi: 10.1097/INF. Ob013e318275614b PMID: 23558320.

33. Moore MR. Update on Effectiveness and Impact of PCV13 use among U.S. Children. US Center for Disease Control 2014.

34. Palmu AA, Jokinen J, Borys D, Nieminen $H$, Ruokokoski E, Siira L, et al. Effectiveness of the ten-valent pneumococcal Haemophilus influenzae protein D conjugate vaccine (PHiD-CV10) against invasive pneumococcal disease: a cluster randomised trial. The Lancet. 2013; 381(9862):214-22.

35. Food and Drug Administration Philippines Center for Drug Registration and Research. Pneumococcal Polysaccharides and Non-Typeable Haemophilus Influenzae (NTHI) protein D conjugate.Vaccine, adsorbed (Synflorix) 0.5 mL Suspension for Injection BR-685, BR-800 \& BR-861 [GDS12/IPI13]. 2014.

36. Assessment Report for Synflorix [Internet]. 2009. Available: http://www.ema.europa.eu/docs/en_GB/ document_library/EPAR_-_Public_assessment_report/human/000973/WC500054349.pdf.

37. Rückinger S, Dagan R, Albers L, Schönberger K, von Kries R. Immunogenicity of pneumococcal conjugate vaccines in infants after two or three primary vaccinations: a systematic review and meta-analysis. Vaccine. 2011; 29(52):9600-6. doi: 10.1016/j.vaccine.2011.09.011 PMID: 21933696

38. Dagan R. The potential effect of widespread use of pneumococcal conjugate vaccines on the practice of pediatric otolaryngology: the case of acute otitis media. Current opinion in otolaryngology \& head and neck surgery. 2004; 12(6):488-94.

39. Musher DM. Pneumococcal vaccine-direct and indirect ("herd") effects. New England Journal of Medicine. 2006; 354(14):1522. PMID: 16598050

40. Salo H, Sintonen H, Pekka Nuorti J, Linna M, Nohynek H, Verho J, et al. Economic evaluation of pneumococcal conjugate vaccination in Finland. Scandinavian journal of infectious diseases. 2005; 37(1112):821-32. PMID: 16308215

41. Butler JR, McIntyre P, Raina MacIntyre C, Gilmour R, Howarth AL, Sander B. The cost-effectiveness of pneumococcal conjugate vaccination in Australia. Vaccine. 2004; 22(9):1138-49.

42. Bin-Chia Wu D, Chang C-J, Huang Y-C, Wen Y-W, Wu C-L, Fann CS-J. Cost-effectiveness analysis of pneumococcal conjugate vaccine in Taiwan: a transmission dynamic modeling approach. Value in Health. 2012; 15(1):S15-S9. doi: 10.1016/j.jval.2011.11.013 PMID: 22265061

43. Average exchange rate Philippine Peso per US Dollar December 2013 [Internet]. [cited 04/12/2013]. Available: http://www.x-rates.com/average/?from=USD\&to=PHP\&amount=1.00\&year=2013.

44. MIMS Philippines. Prevenar 13 and Synflorix 2013 [cited 2013 December 6]. Available: http://www. mims.com/Philippines.

45. Immunization standards, WHO prequalified vaccines, February 2014 [Internet]. [cited 21/02/2014]. Available: http://www.who.int/immunization_standards/vaccine_quality/PQ_199_Pneumococcal_ GSK_2dose/en/.

46. EPPI-Centre Cost Converter [Internet]. 2014 [cited 01/03/2014]. Available: http://eppi.ioe.ac.uk/ costconversion/Default.aspx.

47. Kulpeng W, Sornsrivichai V, Chongsuvivatwong V, Rattanavipapong W, Leelahavarong P, Cairns J, et al. Variation of health-related quality of life assessed by caregivers and patients affected by severe childhood infections. BMC pediatrics. 2013; 13(1):1-9. 
48. Miller E, Andrews NJ, Waight PA, Slack MP, George RC. Effectiveness of the new serotypes in the 13valent pneumococcal conjugate vaccine. Vaccine. 2011; 29(49):9127-31. doi: 10.1016/j.vaccine.2011. 09.112 PMID: 21983361

49. National Center for Pharmaceutical Access and Management Department of Health Philippines. Minutes of the Fourth Meeting of the Formulary Executive Council on 07 June 2013.

50. Weinberger DM, Malley R, Lipsitch M. Serotype replacement in disease after pneumococcal vaccination. The Lancet. 2011; 378(9807):1962-73.

51. Pelton SI, Huot H, Finkelstein JA, Bishop CJ, Hsu KK, Kellenberg J, et al. Emergence of 19A as virulent and multidrug resistant pneumococcus in Massachusetts following universal immunization of infants with pneumococcal conjugate vaccine. The Pediatric infectious disease journal. 2007; 26(6):468-72. PMID: 17529860

52. Hackel M, Lascols C, Bouchillon S, Hilton B, Morgenstern D, Purdy J. Serotype prevalence and antibiotic resistance in Streptococcus pneumoniae clinical isolates among global populations. Vaccine. 2013; 31(42):4881-7. Epub 2013/08/10. doi: 10.1016/j.vaccine.2013.07.054 PMID: 23928466.

53. Gonzalez Martinez F, Navarro Gomez ML, Saavedra Lozano J, Santos Sebastian MM, Rodriguez Fernandez R, Gonzalez Sanchez M, et al. [Emergence of invasive pneumococcal disease caused by nonvaccine serotypes in the era of the 7-valent conjugate vaccine]. Anales de pediatria (Barcelona, Spain: 2003). 2014; 80(3):173-80. Epub 2013/06/26. doi: 10.1016/j.anpedi.2013.05.003 PMID: 23796611.

54. Falup-Pecurariu O. Lessons learnt after the introduction of the seven valent-pneumococcal conjugate vaccine toward broader spectrum conjugate vaccines. Biomedical journal. 2012; 35(6):450-6. Epub 2013/02/28. doi: 10.4103/2319-4170.104409 PMID: 23442357.

55. Whitney CG, Pilishvili T, Farley MM, Schaffner W, Craig AS, Lynfield R, et al. Effectiveness of sevenvalent pneumococcal conjugate vaccine against invasive pneumococcal disease: a matched case-control study. The Lancet. 2006; 368(9546):1495-502.

56. Vesikari T, Wysocki J, Chevallier B, Karvonen A, Czajka H, Arsène J-P, et al. Immunogenicity of the 10 -valent pneumococcal non-typeable Haemophilus influenzae protein D conjugate vaccine (PHiDCV) compared to the licensed 7vCRM vaccine. The Pediatric infectious disease journal. 2009; 28(4): S66-S76. doi: 10.1097/INF.0b013e318199f8ef PMID: 19325449

57. Van Hoek AJ, Andrews N, Waight PA, George R, Miller E. Effect of serotype on focus and mortality of invasive pneumococcal disease: coverage of different vaccines and insight into non-vaccine serotypes. PloS one. 2012; 7(7):e39150. doi: 10.1371/journal.pone.0039150 PMID: 22815698 